ROYO, Manuela. "Derecho Penal e interculturalidad como manifestación del principio de igualdad".

Polít. crim. Vol. 10, № 19 (Julio 2015), Art. 12, pp. 362-389.

[http://www.politicacriminal.cl/Vol_10/n_19/Vol10N19A12.pdf]

\title{
Derecho Penal e interculturalidad como manifestación del principio de igualdad.
}

Penal Law and interculturality as a manifestation of the principle of equality.

\author{
Manuela Royo Letelier \\ Abogada y Licenciada en Historia \\ royo.manuela@gmail.com
}

\section{Resumen}

La historia del Estado chileno y su relación con los pueblos indígenas ha estado marcada por el conflicto y la desigualdad. El presente trabajo analiza críticamente la relación entre el derecho penal del Estado chileno y los pueblos originarios, describiendo las distintas perspectivas desde donde se ha perpetuado un modelo que desconoce la existencia de una cultura diferente. Mediante el análisis de jurisprudencia penal de distintos tribunales chilenos, se constata la existencia de un modelo de desigualdad jurídica, que desconoce la existencia de la cultura indígena, restándole valor a sus mecanismos de resolución de conflictos y a la producción de sus propias normas.

Palabras clave: Derecho penal, colonialismo jurídico, interculturalidad, principio de igualdad, pueblos indígenas

\begin{abstract}
The history of Chilean State and its relationship with indigenous peoples has been marked by inequality and conflicts. This paper critically analyses the relationship between Chilean Criminal Law and the indigenous peoples, describing different perspectives that have perpetuated the denial of a different culture. By means of analyzing case law of different Chilean Criminal Courts, the existence of a model of legal inequality is established, model that doesn't recognize the existence of an indigenous culture, undermining worth to its conflict resolution mechanisms and production of own rules.
\end{abstract}

Key words: Criminal law, legal colonialism, interculturality, principle of equality, indigenous peoples

\section{Aproximación histórica al conflicto cultural.}

El estado actual de la relación entre los pueblos indígenas y el Estado chileno, hace necesaria una revisión desde los orígenes del antiguo encuentro y posterior enfrentamiento entre ambas culturas. El denominado "conflicto indígena" tiene múltiples aristas y especificidades, a continuación analizaremos la que corresponde al ámbito de las normas jurídicas, y de todas éstas nos enfocaremos en las normas penales, siempre relacionando 


\section{ROYO, Manuela. "Derecho Penal e interculturalidad como manifestación del principio de igualdad".}

esta rama del derecho con la historia y el contexto socio cultural. Esta irrupción de las demandas indígenas -diversa tanto por sus demandas que van desde el reconocimiento estatal hasta la autonomía y la autodeterminación- ha generado cambios relevantes en las políticas de Estado de los gobiernos latinoamericanos, principalmente bajo el amparo del Convenio 169 de la OIT, que entre sus estatutos también incorpora estándares reconocimiento de los pueblos indígenas a nivel penal ${ }^{1}$, como en el caso de México, Ecuador o Bolivia donde existe un reconocimiento expreso de los derechos colectivos de los pueblos indígenas ${ }^{2}$ o en países como Guatemala ${ }^{3}$, Colombia, ${ }^{4}$ o Perú ${ }^{5}$ donde se reconoce la validez de la jurisdicción indígena en materia penal.

Chile ratificó el Convenio 169 de la OIT desde el 2009, lo que hasta el momento no se ha traducido en el reconocimiento constitucional pueblos indígenas, que si bien debe ser comprendido inserto en el ordenamiento jurídico nacional a través del artículo $5^{\circ}$ inciso $2^{\circ}$ de la Constitución que permite incorporar dentro del ordenamiento interno normas contenidas en Tratados Internacionales de Derechos Humanos, no ha sido un imperativo

\footnotetext{
${ }^{1}$ El Convenio 169 incorpora diversas disposiciones en materia penal: Art. 9.1. [...] "Deberán respetarse los métodos a los que los pueblos interesados recurren tradicionalmente para la represión de los delitos cometidos por sus miembros", Art. 9.2. "Las autoridades y los tribunales llamados a pronunciarse sobre cuestiones penales deberán tener en cuenta las costumbres de dichos pueblos en la materia" y 10.1. "Cuando se impongan sanciones penales previstas por la legislación general a miembros de dichos pueblos deberán tenerse en cuenta sus características económicas, sociales y culturales".

${ }^{2}$ En México, la Constitución de 1992 reconoce por primera vez la existencia de los pueblos indígenas, y en el Código Penal Federal incluye normas que obligan a considerar la calidad de indígena de un sujeto al momento de la determinación de la pena o de medidas de seguridad. Incluye además un tipo penal que excluye de responsabilidad a los indígenas por el uso de sustancias psicotrópicas en el contexto de sus ceremonias, en cuyo caso el Ministerio Público no puede iniciar la persecución penal. En Ecuador la Constitución de 2008 también reconoce la diversidad cultural y reconoce la efectividad de las resoluciones de la justicia indígena que no puede ser revisada por la justicia ordinaria, sin embargo no contiene normas especiales en su Código Penal. En Bolivia, desde Carta Fundamental boliviana se reconoce como un Estado pluricultural, sin embargo no posee normas especiales en materia penal. Ver VILLEGAS, Myrna, "Entre la exculpación y la justificación. Apuntes de legislación comparada latinoamericana sobre pluralismo jurídico y derecho penal", Revista de Derecho (Valdivia), Vol. XXV N²2, Diciembre 2012, pp. 177 y ss.

${ }^{3}$ No obstante a no existir un reconocimiento constitucional, sí existen los Juzgados de Paz Comunitarios, que resuelven los conflictos de relevancia penal entre indígenas donde se aplica el derecho consuetudinario.

${ }^{4}$ La Constitución colombiana de 1991 reconoce como principio constitucional la diversidad étnica y cultural y define a las comunidades indígenas como sujetos de derechos colectivos, reconoce el derecho a la jurisdicción indígena, como un derecho colectivo, cuyo titular son las comunidades y no la suma de sus integrantes individuales. En materia sustantiva el Código penal reconoce como causal de inimputabilidad el desconocimiento de la ilicitud de una conducta en base a la diversidad cultural y reconoce la coordinación con autoridades indígenas en materia de ejecución de penas y medidas de seguridad en SEMPER, Frank, "Los derechos de los pueblos indígenas de Colombia en la jurisprudencia de la Corte constitucional" en: http://www.juridicas.unam.mx/publica/librev/rev/dconstla/cont/2006.2/pr/pr3.pdf [visitado el 12.05.2014].

${ }^{5}$ En el caso peruano, Constitución Política reconoce como derecho fundamental la identidad étnica y cultural, como así también reconoce la validez de la jurisdicción indígena, facultando a las comunidades indígenas para aplicar el derecho propio. En materia penal incorpora la causal de exclusión de responsabilidad por "error culturalmente condicionado" Ver HURTADO POZO, José, "El indígena ante el derecho penal: el caso peruano", Anuario 2010, en: https://www.unifr.ch/ddp1/derechopenal/articulos/a_20080526_05.pdf [visitado el 12.05.2014], pp. 59 y ss.
} 
Polít. crim. Vol. 10, № 19 (Julio 2015), Art. 12, pp. 362-389.

[http://www.politicacriminal.cl/Vol_10/n_19/Vol10N19A12.pdf]

para la jurisprudencia nacional, como lo dispuso la Corte de Apelaciones de Concepción el 2 de mayo del 2014 en Sentencia ROL 195-2014, ${ }^{6}$ donde señala que:

"Una sentencia dictada por la comunidad a la que pertenece el imputado o una sanción penal impuesta por ellos, no es compatible con nuestro sistema jurídico nacional, de manera que no tiene aplicación el artículo $9^{\circ}$ antes transcrito. (...)

Como puede apreciarse, el artículo $9^{\circ}$ numeral 1 del Convenio 169 sobre Pueblos Indígenas y Tribales en Países Independientes, al ser incompatible con el sistema constitucional chileno de solución de conflictos penales, no puede tener aplicación para la resolución de una causa criminal”.

A nivel legal, la ley 19.253 de 1993 llamada Ley Indígena establece en su artículo 54, el derecho de hacer valer la costumbre en los juicios sustanciados entre indígenas, estableciendo nuevamente el límite de no contravención a la Constitución. Además otorga la facultad a los jueces de aplicar como eximente o atenuante de responsabilidad la costumbre indígena, exigiendo rendir prueba pericial para ello, pero en la práctica esta norma no ha sido vinculante ya sea porque no se ha acreditado por los representantes de los intervinientes indígenas ${ }^{7}$ o derechamente se considera inconstitucional.

Esta renuencia de órganos jurisdiccionales chilenos a incorporar las normas del Convenio 169 y demás Tratados internacionales de derechos humanos en causas penales contra imputados indígenas ha llevado incluso a que la Corte Interamericana de Derechos Humanos condenara el 2014 al Estado chileno, cuyos tribunales han asumido una connotación racista que vulneraban el derecho a la igualdad, además de las afectaciones de otras garantías fundamentales:

“Adicionalmente, la Corte encontró que en la fundamentación de las sentencias condenatorias se utilizaron razonamientos que denotan estereotipos y prejuicios, lo cual configuró una violación del principio de igualdad y no discriminación y el derecho

\footnotetext{
${ }^{6}$ Recurso de nulidad fundado en una errónea aplicación del derecho del Tribunal de Garantía de Los Angeles, que condeno a un imputado indígena M.V.C condenado por el delito de lesiones graves al interior de la Comunidad pewenche Callaqui, comuna de Alto Bio Bio, en circunstancias de que existía cosa juzgada al haber sido ya sancionado por las autoridades tradicionales indígenas quienes ya lo habían sancionado con la privación de ciertos derechos.

$5^{\circ}$.- Que no está controvertido en autos, la aplicación de la costumbre indígena en materia penal, en particular, para configurar circunstancias eximentes o atenuantes de responsabilidad. Sin embargo, ello no significa, como lo sostiene la defensa, que basta con subsumir los hechos que dio por establecido el tribunal en la causal de justificación, como si se tratara de un simple ejercicio aritmético, sino que, como claramente lo regula el artículo 54 inciso segundo de la Ley 19.253, es menester que las conductas constitutivas de la costumbre, que en la especie configurarían las circunstancias modificatorias de responsabilidad penal, deban ser acreditadas en juicio, para lo cual deberán aquéllas probarse por cualquier medio capaz de producir convicción, resultando especialmente relevantes la elaboración de peritajes antropológicos y culturales elaborados por expertos en el tema indígena. Carga procesal esta última, que le empecía a las defensas de los acusados, las que durante el desarrollo del juicio simplificado, no realizaron ninguna actividad en ese sentido, razón por la cual, como acertadamente lo advirtió la juez en el motivo décimo quinto del fallo recurrido "si lo pretendido por la defensa fue el sostener que la conducta de los imputados era la manifestación de una costumbre legalmente establecida como derecho y que ésta era legítima, ello no lo logró, desde que no se explicó, a través de la prueba rendida, el por qué el causar lesiones y amenazar formaba parte de un actuar legítimo". Corte de Apelaciones de Temuco 25.02.2009 rol 99-2009
} 


\section{ROYO, Manuela. "Derecho Penal e interculturalidad como manifestación del principio de igualdad".}

a la igual protección de la ley (supra párrs. 223 a 228 y 230). (...) Todo ello hace que sean condenas arbitrarias e incompatibles con la Convención Americana" 8 .

Lo cierto, es que en nuestro país existen pueblos indígenas, los que de acuerdo a la definición del artículo 1.1 b) del Convenio 169 de la OIT, corresponden a todos quienes:

"por el hecho de descender de poblaciones que habitaban en el país o en una región geográfica a la que pertenece el país en la época de la conquista o la colonización o del establecimiento de las actuales fronteras estatales y que, cualquiera que sea su situación jurídica, conservan sus propias instituciones sociales, económicas, culturales y políticas, o parte de ellas"

Esto pueblos corresponden al pueblo mapuche, rapa nui, aymara, atacameños, quechuas, collas, kawashkar y yamanas ${ }^{9}$. De ellos, la mayoría corresponde al pueblo mapuche ${ }^{10}$, cuya vida y cultura ha trascendido en el tiempo debido a las particularidades propias de su historia y de su relación con los colonizadores, y hoy pese al proceso de mestizaje y a las trashumancias desde el campo hacia la ciudad, persiste como una identidad que se recrea y cobra importancia en la configuración del escenario político social del siglo XXI.

Es importante recordar que de los pueblos que habitaban el territorio americano a la llegada de los conquistadores, el pueblo mapuche tiene la particularidad de haber resistido al ejercito conquistador y ser reconocido implícitamente como una nación independiente, estableciendo una frontera en el río Bio Bio, donde a través de Parlamentos se realizaron tratados de libre comercio, y en forma muy particular, se forjó una relación diplomática en términos de diálogo e intercambio comercial:

"la resistencia indígena no sólo había degastado el proyecto colonial de los conquistadores del siglo XVI, también había obligado a los españoles a buscar otros caminos para permanecer en el reino. Se inauguraba con esto una etapa en las relaciones fronterizas inspirada en una suerte de "pacto colonial" que involucraba a casi todos los protagonistas del mundo fronterizo. La guerra de conquista, la resistencia indígena y la violencia que envolvieron a la empezaban a ser reemplazadas por otras formas de relaciones, más propias de un espacio fronterizo compartido por dos

\footnotetext{
${ }^{8}$ CORTE INTERAMERICANA DE DERECHOS HUMANOS, Caso Norín Catriman y otros (dirigente, miembros y activista del pueblo indígena mapuche vs. Chile, en: http://www.corteidh.or.cr/docs/casos/articulos/seriec_279_esp.pdf, p.137.

${ }^{9}$ De acuerdo al artículo $1^{\circ}$ inciso $2^{\circ}$ de la Ley 19.253, el Estado chileno “(...) reconoce como principales etnias indígenas de Chile a: la Mapuche, Aimará Rapa Nui o Pascuences, la de las comunidades Atacameñas, Quechuas y Collas del norte del país las comunidades Kawashkar o Alacalufe y Yamana o Yagan de los canales australes. El Estado valora su existencia por ser parte esencial de las raíces de la Nación chilena, así como su integridad y desarrollo, de acuerdo a sus costumbres y valores."

${ }^{10}$ La población indígena en Chile, de acuerdo con el censo del año 2002, corresponde al 4,6\% de la población (equivalentes a 692.192 personas), las que se consideran pertenecientes a uno de los ochos pueblos establecidos en la Ley Indígena, destacando el pueblo mapuche (87,3\%), los aymará (7\%) y finalmente los atacameños (3\%). El resto de las etnias reconocidas, suman en su conjunto un 2.7\% (Alacalufe, Colla, Quechua, Rapanui y Yamana).
} 
Polít. crim. Vol. 10, № 19 (Julio 2015), Art. 12, pp. 362-389.

[http://www.politicacriminal.cl/Vol_10/n_19/Vol10N19A12.pdf]

sociedades diferentes, pero dispuestas a convivir bajo condiciones favorables a los dos" $" 11$.

Por ello es que, si bien los primeros contactos entre los mapuches y sistema normativo occidental comienzan en el siglo XVI, al existir una frontera que dividía el territorio de la colonia española del territorio de los mapuches, no fue sino hasta fines del siglo XIX que el Estado chileno traspasa las fronteras políticas y también culturales, cuando comienza a confrontarse el sistema normativo estatal con las normas propias de la cultura ancestral.

Como esbozamos, esta independencia económica, iba de la mano con un sistema político autónomo de la corona española, organizado en distintos territorios y bajo el liderazgo de autoridades tradicionales, quienes eran los encargados de parlamentar con los españoles y de dirigir a los integrantes de las familias que convivían en un territorio, bajo normas y patrones de conductas propias de su cultura ancestral, que se traspasaba de forma oral de generación en generación:

"Los mapuche eran un pueblo política, territorial y económicamente independiente, con una estructura social compleja y flexible basada en unidades de parentesco cuyas autoridades ejercían jurisdicción sobre la base del admapu (derecho indígena) sobre los territorios que ocupaban y que, dependiendo de las necesidades, establecían alianzas temporales y/o coyunturales con otros grupos. Estos lof, base del sistema social, estaban íntimamente relacionados con el sistema económico, ya que al tener el linaje un territorio bajo su control, distribuía su uso entre sus miembros con un patrón de ocupación y explotación rotativo. Se trataba de grupos trashumantes que se movilizaban cíclicamente por su territorio, estableciendo un sistema de redes sociales, políticas y económicas que garantizaban la reproducción biológica, social y cultural de la población" $" 12$.

Tras la guerra de independencia criolla y el incipiente nacimiento la República chilena, que las miradas del poder apuntan hacia la incorporación de las tierras mapuche, bajo el ideario de una gran nación chilena, que debía incorporar a los indígenas bajo el mismo Estado, bajo la misma "chilenidad". La consolidación del Estado chileno requería la inclusión de nuevos territorios que permitieran un mayor desarrollo económico, necesitaban también de mano de obra que pudiera incorporarse a esta nueva nación.

Para forjar este nuevo proyecto de desarrollo capitalista era imperiosa la formación de una identidad nacional, y para forjar esta nueva identidad chilena se requerían elementos que aportaran en una subjetividad colectiva, en un proyecto nacional de desarrollo. Este ideario se realizó mediante diversos mecanismos de construcción de un sentido común mediante los clásicos dispositivos de normalización y de estructuración de una sociedad moderna y liberal, entre ellos los más relevantes fueron la educación y por supuesto, las normas jurídicas.

\footnotetext{
${ }^{11}$ PINTO, Jorge, La formación del Estado y la nación y el pueblo mapuche. De la inclusión a la exclusión, Santiago: DIBAM, 2003, p. 26.

${ }^{12}$ CEPAL, "Desigualdades territoriales y exclusión social del pueblo mapuche en Chile", (2012), p. 28, en http://www.cepal.org/publicaciones/xml/3/46283/2012-79-DesigualdadesterritorialesWEB.pdf, [visitado el 28.10.2014].
} 
ROYO, Manuela. "Derecho Penal e interculturalidad como manifestación del principio de igualdad".

Por ello, desde la formación del Estado Nación unitario, se apuntó hacia un orden jurídico único y homogéneo para todos los habitantes del territorio -ahora chileno-, que replicara los sistemas normativos europeos que fueron modelos y referentes de la incipiente legislación. En este sentido, resulta interesante la discusión legislativa que se produjo al redactar la Constitución Política de 1823, y que grafica lo que anteriormente expusimos, en palabras del diputado Gaspar Marín:

"los araucanos i demás indijenas -dijo Marín-, se han reputado como naciones; con ellos se han celebrado tratados de paz i otras estipulaciones y lo que es más, en los parlamentos se han fijados los límites de cada territorio, cosa que no se practica sino entre naciones distintas i reconocidas i no puedo comprender que al presente el Congreso se proponga darles leyes, no como a nación i si como a hombres reunidos, sin explorar su voluntad, sin preceder una convención y sin ser representados en la legislatura" 13

Sin embargo, los constituyentes desecharon reconocer la existencia de la nación mapuche, y consideraron que los indígenas eran parte de la nación chilena, omitiendo y con ello inferiorizando su identidad, su cultura y su historia propia bajo un ideario de proyecto nacional unitario que se perpetua hasta nuestros días.

Tal como se expondrá en el presente trabajo, la homogeneización cultural y el desconocimiento de la diversidad cultural se forjaron, se recrean y se refuerzan con la creación y aplicación de normas jurídicas.

En el derecho comparado y en particular en el área de la antropología jurídica, se ha denominado como "monismo jurídico" al paradigma de acuerdo al cual, la única fuente del derecho es el Estado. Solo desde el Estado, como productor de normatividad es desde donde emanan normas de conducta de una sociedad, las cuales deben cumplir con determinado orden, ser escritas, codificadas, para adquirir la validez que les proporciona su fuerza normativa:

"En un principio, se diría que la íntima conexión entre la suprema racionalización del poder soberano y la positividad formal del Derecho conduce a la fusionada y predominante doctrina del monismo. Tal concepción atribuye al Estado moderno el monopolio exclusivo de la producción de las normas jurídicas, o sea, el Estado es el único agente legítimo capaz de crear legalidad para encuadrar las formas de relaciones sociales que se van imponiendo ${ }^{14}$."

Vinculando este análisis hacia el proceso de conquista y colonización cultural, el Estado como ente exclusivo generador de normas y fuente única de derechos- desplegó sobre la costumbre indígena una forma de dominación cultural, que se cristalizó en la imposición de leyes exógenas a las normas de conducta ancestrales, bajo una falsa idea de igualdad que uniformó las diversas prácticas normativas en un solo Estado de Derecho.

\footnotetext{
${ }^{13}$ Sesión n42 del 9 de junio de 1828, en PINTO, La formación, cit. nota ${ }^{\circ}$ 11, p. 111.

${ }^{14}$ WOLKMER, Antonio Carlos, Pluralismo Jurídico. Fundamentos de una nueva cultura del derecho, Madrid: Editorial MAD, 2006, p. 56.
} 
Polít. crim. Vol. 10, № 19 (Julio 2015), Art. 12, pp. 362-389.

[http://www.politicacriminal.cl/Vol_10/n_19/Vol10N19A12.pdf]

Bajo este esquema - un Derecho, un Estado, una Nación- la llamada "Pacificación de la Araucanía"15, encuentra su fundamento y se transforma en una cruzada civilizadora que mediante las armas expulsó a los mapuche de sus territorios para luego donarlos a familias de colonos, que portaban consigo la racionalidad y el proyecto de la modernidad liberal.

Este plan colonizador en territorio indígena fue la manifestación del interés de la elite liberal por expandir el Estado chileno hacia la modernidad y la civilización, que sólo se podía obtener replicando los modelos europeos que educaran y regeneraran a la raza inferior de los indígenas, discurso plasmado en los debates del Parlamento chileno, en los periódicos nacionales, y en todos aquellos espacios donde se deliberaba sobre el proyecto nacional. ${ }^{16}$

Lo grave es que inserto en este ideario moderno y civilizador, está el discurso colonial cuya base es la distinción social según la raza, donde el blanco occidental y su sistema de vida es considerado superior al negro, indígena o mestizo. Si bien este modelo comenzó a gestarse en América desde la época de la conquista en adelante, se desplegó de la mano del sistema liberal capitalista de organización política y económica, siempre bajo pretensión eurocéntrica de las elites, que buscaron promover formas de vida, de producción de conocimientos y de normas, que reprodujeran los cánones europeos de comportamiento social y moral. Todo ello en territorios expropiados a los antiguos habitantes indígenas, a quienes excluyeron de este nuevo desarrollo social ${ }^{17}$.

En el campo jurídico, este modelo colonial se instaló en todo el continente latinoamericano, traduciendo y copiando las leyes, Códigos y Constituciones ya vigentes en España, Francia entre otros países del primer mundo, lo cual es posible apreciar en la historia de la ley de estos cuerpos legales y en el modelo de codificación propio del siglo XIX europeo. Es más, nuestro Código penal de 1847 -vigente hasta la fecha- tomó como modelo el Código Penal español de 1848, e incorporó elementos del Código Penal Belga de 1867, ambos derivados del Código Penal Francés ${ }^{18}$, y con algunas variaciones, repitió su estructura interna y tipos penales, sin hacer un guiño siquiera a la existencia de raíces originarias en el territorio nacional.

\footnotetext{
${ }^{15}$ Eufemismo utilizado para llamar al periodo posterior a 1861 donde el ejército chileno invadió el territorio indígena mapuche, y mediante las armas despojó a sus habitantes de sus territorios ancestrales. En MARIMAN, Pablo, "Elementos de historia mapuche" en: http://www.ihes.com/mar/mp1.htm, p. 3, [visitado el 19.01.2014].

16 “Aunque los planteamientos de la Vicuña Mackenna y de otros intelectuales que escribieron en El Mercurio de Valparaíso y el Ferrocarril de Santiago fueron rebatidos por distintos sectores de la sociedad nacional, el positivismo que los inspiraba causó estragos en la valoración de nuestra cultura e identidad, acentuando una actitud de admiración por Europa que transformó la inmigración en una posibilidad, no solo de poblar el territorio, sino de moralizar a los chilenos y traspasarle los valores que nuestra clase dirigente consideraba apropiados para la nación PINTO, La formación, cita nota $\mathrm{n}^{\circ} 11$, p. 119.

17 Ver QUIJANO, Aníbal, “Colonialidad del poder, eurocentrismo y América Latina”. En: LANDER, Edgardo (Comp.), La colonialidad del saber: eurocentrismo y ciencias sociales. Perspectivas Latinoamericanas. Buenos Aires: CLACSO, Consejo Latinoamericano de Ciencias Sociales, 2000. p. 246.

18 PEÑA, Silvia, "Las raíces histórico culturales del derecho penal chileno", Revista de Estudios HistoricoJuridicos, $\quad \mathrm{N}^{\circ} \quad 7, \quad$ Chile, $\quad 1982, \quad$ en http://www.restudioshistoricos.equipu.cl/index.php/rehj/article/viewFile/97/95 pp. 312 y ss. [visitado el 28.10.2014].
} 


\section{ROYO, Manuela. "Derecho Penal e interculturalidad como manifestación}

del principio de igualdad".

De esta manera se importó directamente desde Europa un código de tipificación de normas de conducta y de sanción que por la vía coactiva impuso un estándar de comportamiento conforme a los patrones coloniales, y tal como en otros países de América, se fue configurando un modo de ser y de actuar en sociedad único y estandarizado. Este nuevo discurso jurídico de los dominadores disolvió las particularidades y diversidades culturales "en una forma de ciudadanía única que, sin explicitarlo, coincide con el hombre medio de la cultura hegemónica, presentado como el arquetipo del sujeto abstracto normal"19 , modelo que se perpetuó durante los años tanto en las sentencias de los tribunales nacionales, como así también en la elaboración normativa de un Estado que hasta el momento ni siquiera ha reconocido la existencia de los pueblos indígenas a nivel constitucional.

Este desconocimiento de los derechos fundamentales de los pueblos indígenas a nivel constitucional, no es más que el reflejo de una sociedad que no es capaz de comprender que la existencia de los pueblos indígenas como agentes de derechos propios, en base a su historia y a su cosmovisión, cuyo reconocimiento como sujetos de derechos es parte de un resarcimiento que como país debe realizarse luego del despojo territorial, que ha sumido al pueblo mapuche en un estado de pobreza y exclusión social.

Por ello, la validez de una ley que nace y se reproduce en un contexto de desigualdad social y cultural, como la que vive hoy el pueblo mapuche, parece bastante cuestionable, y hacen eco las palabras del constitucionalista argentino Roberto Gargarella, quien critica las normas penales propias de nuestra realidad latinoamericana actual:

"Detengámonos a reflexionar, a continuación, sobre el caso de las normas penales originadas en sociedades marcadas por la pobreza y la desigualdad, es decir, comunidades socialmente injustas. En estos casos, -podemos asumir y anticipar, razonablemente- existe un riesgo muy alto de que los medios coercitivos del Estado sean manipulados para proteger un orden social injusto. Es decir, en estas situaciones existen fuertes chances de que un pequeño grupo -el más beneficiado dentro de ese contexto de desigualdad y pobreza- utilice su poder de influencia para apropiarse del proceso de creación normativa (o presionar indebidamente sobre el mismo) de modo tal de orientar el uso de la coerción estatal a su favor. En el peor de los casos, dicho orden represivo puede utilizarse para custodiar la propia situación aventajada, persiguiendo y sancionando penalmente a aquellos que, de algún modo, osan ponerla en cuestión. Adviértase que, si tal fuera el caso, nos encontraríamos con normas vinculadas con el derecho penal, absolutamente ajenas (por los modos de su creación) a toda o parte de la sociedad, y que son diseñadas por un grupo pequeño, a su servicio, para su propio beneficio. ${ }^{20,}$

${ }^{19}$ SALGADO, Juan Manuel, "Cómo la práctica procesal anula los derechos indígenas", en: OLEA, Helena (Ed.), Derecho y Pueblo Mapuche. Aportes para la discusión. Santiago: Centro de Derechos Humanos UDP, 2013, p. 56.

${ }^{20}$ GARGARELLA, Roberto "El derecho y el castigo: de la injusticia penal a la justicia social" en: http://earchivo.uc3m.es/bitstream/handle/10016/17097/DyL-2011-25-gargarella.pdf?sequence=5, p. 43[visitado el 28.10.2014]. 
Polít. crim. Vol. 10, № 19 (Julio 2015), Art. 12, pp. 362-389.

[http://www.politicacriminal.cl/Vol_10/n_19/Vol10N19A12.pdf]

\section{Derecho penal y Convenio 169.}

Para la teoría del bien jurídico, la función del derecho penal es la protección de bienes jurídicos, entendiéndolos como ciertos condicionantes -estados valorados positivamente como la vida o el patrimonio- de los cuales son titulares los individuos, la comunidad o el Estado.

\section{Siguiendo a Roxin:}

"La misión del Derecho penal está en asegurar a sus ciudadanos un a convivencia libre y pacífica, garantizando todos los derechos establecidos jurídico constitucionalmente. Si esta misión es denominada, a modo de síntesis, protección de bienes jurídicos, por bienes jurídicos han de entenderse todas las circunstancias y finalidades que son necesarias para el libre desarrollo del individuo, la realización de sus derechos fundamentales y el funcionamiento de un sistema estatal edificado sobre esa finalidad" ${ }^{, 21}$.

Desde esta perspectiva, la libertad del ser humano y su desarrollo deben ser resguardados por un ordenamiento jurídico que sancione a quien trasgreda determinadas normas de conducta, que conminan a los ciudadanos a adscribirse a sus mandatos y a dirigir su actuar de la manera en que lo determina el legislador, transgresión que lleva aparejada la imposición de una norma de sanción que afectará su libertad o su patrimonio personal, restringiéndolo o privándolo de sus derechos.

Es innegable el hecho de que el Estado chileno ha ratificado el Convenio 169 de la OIT, que corresponde a un instrumento jurídico internacional de protección de los derechos fundamentales de las personas que integran los pueblos indígenas, como así también los derechos de las mismas comunidades de ejercerlos como agentes de estos derechos colectivos, los cuales incorpora a través del artículo 5 inciso $2^{\circ}$ de la Constitución. Como señala Meza-Lopehandía:

"la Constitución chilena otorga explícitamente un estatus especial a ciertas normas de derecho internacional, específicamente a aquellas relativas a lo que el constituyente llama "derechos esenciales emanados de la naturaleza humana" -y que nosotros entendemos como derechos fundamentales-, contenidas en un tipo específico de fuentes del derecho internacional: los tratados internacionales ratificados por Chile y que se encuentren vigentes, aunque no exclusivamente en ellos"22.

Evidentemente, el Convenio $\mathrm{N}^{\circ} 169$ es un tratado internacional de derechos humanos, y como tal, las normas que contenga que tengan tal carácter, son el límite al ejercicio de la soberanía del Estado chileno, y de su jurisdicción, por lo tanto el respeto de los derechos

\footnotetext{
${ }^{21}$ ROXIN, Claus, "El concepto de bien jurídico como instrumento de crítica legislativa sometido a examen", Revista Electrónica de Ciencia Penal y Criminología, $\mathrm{N}^{\circ} 15 \quad$ (2013), p. 1 , en http://criminet.ugr.es/recpc/15/recpc15-01.pdf . [visitado el 29.05.2015].

${ }^{22}$ MEZA-LOPEHANDÍA, Matías, "El Convenio $\mathrm{N}^{\circ} 169$ de la OIT en el sistema normativo chileno" en: VV.AA., Las Implicancias de la Ratificación del Convenio $N^{\circ} 169$ de la OIT en Chile, en http://www.observatorio.cl/sites/default/files/biblioteca/libro_ley169.pdf [visitado el 29.05.2015], p. 71.
} 
ROYO, Manuela. "Derecho Penal e interculturalidad como manifestación del principio de igualdad".

individuales y colectivos de los indígenas es un presupuesto de legitimidad para las normas penales.

La norma penal para ser legítima debe respaldarse en la protección de bienes jurídicos que pueden ser individuales o colectivos, siempre que se fundamenten en el resguardo del desarrollo de los individuos y en el ejercicio de sus derechos fundamentales. En el sentido contrario, éstas son ilegítimas cuando tienen como objeto un comportamiento que no afecte el libre desarrollo del individuo ni a sus presupuestos sociales, lo que es muy relevante en el ámbito de las relaciones interculturales, ya que una conducta que puede ser delito para el ordenamiento jurídico chileno, puede no serlo para una cultura indígena, y por lo tanto no es legítima su aplicación.

\section{Señala Roxin:}

"En nuestra actual sociedad multicultural es imposible hallar, faltando una afectación de un bien jurídico, un "consenso fundamental" acerca de la necesidad de pena de un determinado comportamiento" 23 .

Por lo tanto, la necesidad de fundamentar las normas penales en la protección de bienes jurídicos es también un mecanismo de legitimar la acción de la norma penal en contextos multiculturales, en donde la función liberal del pensamiento del bien jurídico es también proteger a las minorías y al desarrollo de los derechos fundamentales de quienes las integran.

Como señalamos, el Convenio 169 se aplica a pueblos indígenas y tribales, los que define combinando elementos objetivos, relativos a sus características socioculturales y procedencia histórica (art. 1.1), con el elemento subjetivo de la autoidentificación (art. 1.2), apuntando hacia la preservación de la identidad cultural y de lenguas originarias, y a la aplicación de las normas tradicionales y acceso a justicia, como mecanismos de protección de sus derechos como culturas distintas.

En este último punto, el artículo 8 inciso segundo dispone que:

"dichos pueblos deberán tener el derecho de conservar sus costumbres e instituciones propias, siempre que éstas no sean incompatibles con los derechos fundamentales definidos por el sistema jurídico nacional ni con los derechos humanos internacionalmente reconocidos".

Por lo tanto, si los elementos culturales y la costumbre indígena -entendiendo a ésta como una expresión de una cultura particular-, son parte de los antecedentes de hecho o de derecho que son relevantes al momento de la resolución de un conflicto jurídico, corresponde su incorporación dentro de la aplicación del derecho, impidiendo con ello también, la aplicación de normas penales que no protejan bienes protegidos por la cultura indígena, todo ello en resguardo de sus derechos fundamentales.

${ }^{23}$ ROXIN, "El concepto", cit. nota n ${ }^{\circ} 21$, p. 16. 
Polít. crim. Vol. 10, № 19 (Julio 2015), Art. 12, pp. 362-389.

[http://www.politicacriminal.cl/Vol_10/n_19/Vol10N19A12.pdf]

Sin embargo, ha habido reticencias desde sectores que consideran inconstitucional la incorporación del Convenio 169. El Tribunal Constitucional se ha pronunciado en dos ocasiones sobre el este Tratado, la primera vez, en 2000 y la segunda, en 2008. En la causa Rol No 309, del 4 de agosto de 2000, en el que diversos diputados planteaban que este tratado contravenía las bases de la institucionalidad del Estado chileno al transferir a los pueblos indígena el ejercicio de soberanía exclusivamente radicada en Chile. Como relata Mereminskaya:

"El Tribunal rechazó este planteamiento dado que arribó a la conclusión de "que la expresión 'pueblos indígenas', debe ser considerada en el ámbito de dicho tratado, como un conjunto de personas o grupos de personas de un país que poseen en común características culturales propias, que no se encuentran dotadas de potestades públicas y que tienen y tendrán derecho a participar y a ser consultadas, en materias que les conciernan, con estricta sujeción a la Ley Suprema del respectivo Estado de cuya población forman parte. Ellos no constituyen un ente colectivo autónomo entre los individuos y el Estado" (Considerando 44)"24.

En esta misma sentencia, el Tribunal Constitucional determinó que no es posible aplicar el artículo 9.1 del Convenio 169 ("Deberán respetarse los métodos a los que los pueblos interesados recurren tradicionalmente para la represión de los delitos cometidos por sus miembros"), por considerarlo inaplicable y en consecuencia inidóneo para afectar los principios del ordenamiento jurídico chileno:

" $53^{\circ}$. Que en el ámbito de nuestro derecho procesal constitucional, el artículo $19^{\circ}$, de la Carta Fundamental, en su numeral $3^{\circ}$, al establecer la garantía de la igual protección de la ley en el ejercicio de sus derechos, expresa, en su inciso séptimo, que "Nadie puede ser juzgado por comisiones especiales, sino por el tribunal que le señale la ley y que se halle establecido con anterioridad por ésta" y agrega, en su inciso siguiente, que "Toda sentencia de un órgano que ejerza jurisdicción debe fundarse en un proceso previo, legalmente tramitado."

Lo expuesto permite concluir que el contenido, en esta parte, del artículo $9^{\circ}$, al ser incompatible con el sistema constitucional chileno de solución de conflictos penales, no puede tener aplicación y, como su natural consecuencia, no permite ser tachado de inconstitucional, toda vez que dispone el tratado que la norma en análisis va a recibir aplicación sólo en cuanto sea compatible con el sistema jurídico propio de cada Estado, lo que en el caso de Chile, no ocurre por lo expuesto ${ }^{25} ; "$.

Luego, este tribunal razona que es procedente aplicar el artículo 9.2 ("las autoridades y los tribunales llamados a pronunciarse sobre cuestiones penales deberán tener en cuenta las costumbres de dichos pueblos"), considerándolo un elemento más dentro de los antecedentes sobre los que puede fundamentar una resolución un juez:

" 6 . Que el hecho de que un tratado o la ley entregue al juez nuevos elementos a considerar en una causa, no limita de manera alguna el ejercicio de la plena

\footnotetext{
${ }^{24}$ MEREMINSKAYA, Elina, "El Convenio 169 de la OIT sobre pueblos indígenas y tribales: Derecho internacional y experiencias comparadas”, Estudios Públicos N N $^{\circ} 21$ (2011), p. 288.

${ }^{25}$ TRIBUNAL CONSTITUCIONAL DE CHILE, sentencia rol No 309, 4 de agosto de 2000, considerando $53^{\circ}$
} 
ROYO, Manuela. "Derecho Penal e interculturalidad como manifestación del principio de igualdad".

jurisdicción que le otorga la Carta Fundamental para hacer uso de ella a través del debido proceso" 26 .

En consecuencia, el número $2^{\circ}$ del artículo $9^{\circ}$, en la medida en que autoriza al juez para tomar en cuenta la costumbre, no contraviene la Constitución Política, toda vez que la jurisdicción que ejerce y que, para el caso concreto, se singulariza en su competencia específica, lo autoriza para ponderar todos los elementos de hecho y de derecho ventilados en el proceso, entre los cuales pueden encontrarse las costumbres de los pueblos indígenas, sin que ello violente, de manera alguna, la igualdad ante la ley, y menos, la igual protección de sus derechos ante la justicia que ésta le brinda.

\section{Normas penales y cultura.}

Siguiendo a Cury:

"El derecho penal está constituido por el conjunto de normas que regulan la potestad punitiva del Estado, asociando a ciertos hechos, estrictamente determinados por la ley, como presupuesto, una pena o una medida de seguridad o corrección como consecuencia, con el objeto de asegurar el respeto por los valores elementales sobre los cuales descansa la convivencia humana pacífica" ${ }^{27}$.

Por ello, las normas que prohíben delitos, se fundamentan sobre una valoración previa de cuál es un comportamiento permitido dentro de una sociedad, qué comportamientos deben ser sancionados y cómo. Estas valoraciones sociales corresponden a representaciones colectivas que son parte de una cultura específica y de una identidad étnica también.

De hecho, la noción de lo prohibido y lo permitido, es una manifestación de las creencias y valores integrados, que corresponden a la subjetividad o sentido común que tiene cada cultura. Estas valoraciones varían de un momento histórico a otro, de una sociedad a otra y evidentemente de una cultura a otra, y evidentemente se manifiestan de forma diversa dependiendo del contexto cultural de donde provengan. En este sentido Stavenhagen:

"Es bien sabido que el concepto y la identificación de un delito es la resultante de circunstancias históricas y contextos culturales. Por ello no es sorprendente que con frecuencia lo que la ley nacional tipifica como un delito no lo es para una comunidad indígena, o, por el contrario, una infracción social sujeta a castigo en una comunidad indígena (es decir, un delito en lenguaje jurídico) puede no ser reconocido como tal por la legislación penal vigente. ${ }^{28,}$

Ejemplos típicos de estas consideraciones se pueden ver en el caso del uso de la hoja de coca en los pueblos indígenas quechua y aymara, circunstancia que es considerado por el

\footnotetext{
${ }^{26}$ TRIBUNAL CONSTITUCIONAL DE CHILE, sentencia rol No 309, 4 de agosto de 2000, considerando $53^{\circ}$

${ }^{27}$ CURY, Enrique, Derecho Penal. Parte General, Santiago: Ediciones Universidad Católica de Chile, 2001, 6 ad., p. 37.

${ }^{28}$ STAVENHAGEN, Rodolfo, "Los derechos de los indígenas: algunos problemas conceptuales", Nueva Antropología Vol. XIII, 43 (1992), p. 84.
} 
Polít. crim. Vol. 10, № 19 (Julio 2015), Art. 12, pp. 362-389.

[http://www.politicacriminal.cl/Vol_10/n_19/Vol10N19A12.pdf]

derecho chileno una infracción a ley de $\operatorname{drogas}^{29}$, pero que en países como Perú o Bolivia es un acto atípico debido a que corresponde a un alimento tradicional de la población indígena, que se utiliza como medicina, y en contextos rituales y ceremoniales ${ }^{30}$.

\section{Al respecto, Hurtado Pozo señala:}

"el individuo es siempre producto y portador de cultura, al igual que el derecho (tanto más el derecho penal), que es una manifestación de la cultura. Se puede decir, por lo tanto, que individuo y derecho se encuentran estrechamente relacionados, de modo que la aplicación de este último implica tener en cuenta el contexto cultural en que se da y el bagaje cultural del individuo concernido" $" 31$.

El desconocimiento de la cultura indígena en las normas penales chilenas ha derivado a que únicamente el ordenamiento jurídico penal reconozca las valoraciones de cultura occidental de raigambre filosófica liberal, cuyo punto de referencia es el "hombre medio", que claramente no es indígena. El construir normas jurídicas que miran desde y hacia un prototipo de ciudadano modelo se produce una inferiorización de las modalidades divergentes, o formas de ver el mundo y de actuar distintas al patrón hegemónico desde el cual se construye el ordenamiento jurídico. Esta inferiorización cultural a través de la ley conlleva a una realidad de desigualdad jurídica, donde el prototipo de ciudadano occidental es valorado de una forma privilegiada, a diferencia de aquellos cuyo comportamiento divergente es desvalorado por la norma, dándole un trato inferior, o derechamente castigando su actuar.

Esta realidad de desigualdad jurídica corresponde al correlato de una desigualdad social, de una historia que excluyó a los pueblos indígenas de la construcción del Estado y de la política, y que hoy se sigue re-produciendo en la aplicación misma de las normas jurídicas.

Bajo esta perspectiva, es que el presente trabajo busca ejemplificar cómo los tribunales chilenos históricamente han sido mecanismos de reproducción de lógicas de desigualdad y de injusticia social con los pueblos indígenas, en particular en el ámbito del derecho penal, entendiendo este ámbito del derecho como un medio de coacción impuesto a ciudadanos y ciudadanas para proteger bienes jurídicos ${ }^{32}$. En este sentido, el fin de la norma penal es la prohibición de determinadas conductas que atenten contra estos bienes jurídicos o sean potencialmente riesgosas, por lo tanto limitan la capacidad de actuar de quienes interactúan en sociedad.

29 Decreto Supremo $N^{\circ} 867$ que sanciona el tráfico ilícito de estupefacientes y sustancias sicotrópicas y sustituye ley 19.366, Artículo 2: "Califícase como sustancias o drogas estupefacientes o sicotrópicas, productoras de dependencia física o síquica, a que se refiere el inciso segundo del artículo $1^{\circ}$ de la Ley $\mathrm{N}^{\circ}$ 20.000, que no producen los efectos indicados en su inciso primero, a las siguientes: (...) Coca, hoja de"

${ }^{30}$ BARRIENTOS PARDO, Ignacio, "Licitud del porte y uso de la hoja de coca", Política Criminal N5 (2008), pp.1-30, en: http://www.politicacriminal.cl/n_05/a_4_5.pdf [visitado el 05.11.2014].

${ }^{31}$ HURTADO POZO, "El indígena", cit. nota $\mathrm{n}^{\circ}$ 5, p. 118.

${ }^{32}$ Los bienes jurídicos son definidos por la doctrina funcionalista como "circunstancias o finalidades que son útiles para el individuo y su libre desarrollo en el marco de un sistema global estructurado sobre la base de esa concepción de los fines o para el funcionamiento del propio sistema", mediante la vigencia de las prohibiciones, y así, mantener las normas de conducta. En ROXIN, Claus, Derecho Penal, Parte General. España: Editorial Civitas, 1999, p. 56. 


\section{ROYO, Manuela. "Derecho Penal e interculturalidad como manifestación} del principio de igualdad".

Estos bienes jurídicos, como todo constructo cultural, pueden transformarse y mutar dependiendo del momento histórico en que son valorados, por ejemplo antiguamente se sancionaba penalmente el adulterio, el incesto o la bigamia y hoy son impunes, $\mathrm{y}$ actualmente se sancionan conductas que antes no eran valoradas por la sociedad, como por ejemplo el maltrato animal o el manejo en estado de ebriedad. Pero la sociedad no puede funcionar solo en base a restricciones de libertad, por lo cual, se realiza una ponderación de intereses que no sólo sirven para determinar una norma de conducta, sino que también es útil para definir el ámbito de responsabilidad de una persona en relación a su competencia $^{33}$. Hay conductas que se consideran permitidas, dentro de ámbitos de responsabilidad que también son valorados por normas jurídicas. Todas estas valoraciones corresponden a parámetros culturales previamente establecidos, y que por consiguiente difieren entre una cultura y otra, cambian durante la historia. Así, las conductas realizadas por un sujeto para que constituyan delito y por lo tanto atenten contra bienes jurídicos deben adecuarse a la descripción que hace la ley de tal comportamiento, lo que constituye el tipo penal.

Por ello, dentro de un contexto de desigualdad socio cultural, manifestado en un sistema jurídico colonial $^{34}$ los bienes protegidos corresponden a los intereses y valoraciones de quienes se encuentran en una posición hegemónica, cuya representatividad en los espacios de poder hacen proyectar sus intereses en la tipificación y aplicación de normas penales, lo cual se transforma en un mecanismo de discriminación y reproducción de dominación cultural.

Constatada esta situación, corresponde buscar las herramientas teóricas que apunten a revertirla, intentando construir un relato contrahegemónico que pueda ser un aporte a la construcción de un sistema jurídico más equitativo y justo. Para ello, es necesario asumir la existencia de una cultura distinta a la occidental, que tiene una forma particular de comprender el mundo, de determinar su manera de relacionarse y que históricamente construyó normas, autoridades y procedimientos. Para la antropología jurídica esta es la tarea que realiza la teoría de la interculturalidad.

El concepto de interculturalidad ha sido acuñado desde las ciencias sociales como una teoría política y filosófica que valora la existencia de culturas no occidentales, critica la perspectiva eurocentrista de formación de conocimientos y apunta a la deconstrucción y cuestionamiento de la pretensión universalista de la mirada occidental:

\footnotetext{
33 "La sociedad nos es un mecanismo cuyo único fin sea ofrecer la máxima protección a los bienes jurídicos, sino que está destinada a posibilitar las interacciones, y la prohibición de cualquier puesta en peligro, sea de índole que sea, haría imposible la realización de cualquier comportamiento social, incluyendo también los comportamientos de salvación". En JAKOBS, Gunther, Estudios de Derecho Penal, Madrid: Editorial Civitas, 1997 p. 28.

34 "El colonialismo es todo sistema de naturalización de las relaciones de dominación y de subordinación basadas en diferencias étnicas o raciales. El Estado moderno es monocultural y es colonial en ese sentido, porque sus instituciones siempre han vivido a partir de una norma, que es una norma eurocéntrica que no celebra sino, al contrario, oculta la diversidad". En DE SOUSA SANTOS, Boaventura, Justicia indígena, Plurinacionalidad e interculturalidad en Bolivia, La Paz: Ediciones Abya-Yala, 2012, p. 21.
} 
Polít. crim. Vol. 10, № 19 (Julio 2015), Art. 12, pp. 362-389.

[http://www.politicacriminal.cl/Vol_10/n_19/Vol10N19A12.pdf]

"La Filosofía Intercultural tiene una doble intención: por un lado, una crítica radical a todo tipo de etno y culturocentrismo en la filosofía, lo que implica el reconocimiento fundamental de la "culturalidad" y 'contextualidad' cultural, social, histórica y política de cada filosofar. Por otro lado, el planteamiento de un nuevo relacionamiento entre distintas/os, a través de un diálogo o múltiples diálogos (polílogos) interculturales, en términos de la simetría y equidad"35.

Este camino no parece fácil en el status quo nacional, partiendo de la base de la inexistencia de un reconocimiento constitucional a los pueblos originarios, la inserción de una perspectiva intercultural en materia penal -en base a la aceptación de la existencia de una especificidad indígena en materia de normatividad- puede entenderse como un medida inconstitucional, que otorga un estatus privilegiado para un determinado sector de la sociedad nacional. Es por ello que el reconocimiento de las características propias de los indígenas en materia penal ha sido considerado un atentado a la soberanía nacional -ya que presupone la existencia de una nación que se rige por leyes propias-como así también al principio de unidad jurídica.

En efecto, esta fue la argumentación levantada justamente en requerimiento de inconstitucionalidad de la Cámara de Diputados cuando se debatió la constitucionalidad de la ratificación del Convenio 169 de la OIT, la aprobación de los art. 9 y $10^{36}$ que justamente incorporan como un criterio relevante en las decisiones judiciales la pertenencia de un sujeto a pueblo indígena al momento de determinar las sanciones penales.

El principal argumento que levantó en contra de la incorporación de estos artículos fue que el reconocimiento de la calidad de indígena de una persona significa realizar una distinción étnica, lo que en sí mismo es un acto racista y arbitrario que atenta contra el principio de igualdad de la ley y en consecuencia es inconstitucional:

"Estas reglamentaciones claramente contravienen el principio de la igualdad ante la ley, pues conminan, en forma perentoria a las autoridades y los tribunales, a considerar las costumbres de dichos pueblos en la aplicación de las sanciones penales, discriminación del todo arbitraria, ya que en razón del origen étnico del delincuente se aplicarán penas diversas a los infractores de iguales delitos, las que según sea la costumbre de dichos pueblos indígenas, pueden ser superiores o inferiores a las penas aplicables al resto de los chilenos. Además, y tal como lo indica el artículo $10 \mathrm{~N}^{\mathrm{o}} 1 \mathrm{del}$ Convenio, cuando se impongan sanciones previstas en la legislación general a miembros de dichos pueblos deberán tenerse en cuenta sus características económicas, sociales y culturales, debiéndose dar la preferencia a tipos de sanción distintos del encarcelamiento. ¿Es acaso importante para la víctima y la sociedad, que un determinado delito sea cometido por un individuo de una etnia u otra? Es claro, vuestra Excelencia, que los artículos 9 y 10 del Convenio atentan contra el principio de

\footnotetext{
${ }^{35}$ ESTERMANN, Josef, Filosofía Contemporánea, La Paz: Ed. Tika y Teko, 2011.

Art. 9.1. [...] “[D]eberán respetarse los métodos a los que los pueblos interesados recurren tradicionalmente para la represión de los delitos cometidos por sus miembros", Art. 9.2. "Las autoridades y los tribunales llamados a pronunciarse sobre cuestiones penales deberán tener en cuenta las costumbres de dichos pueblos en la materia" y 10.1. "Cuando se impongan sanciones penales previstas por la legislación general a miembros de dichos pueblos deberán tenerse en cuenta sus características económicas, sociales y culturales".
} 
ROYO, Manuela. "Derecho Penal e interculturalidad como manifestación del principio de igualdad".

igualdad ante la ley consagrado en el artículo $19, \mathrm{~N}^{\mathrm{o}} 2^{\circ}$ de la Constitución, pues constituye en sí una discriminación que carece de fundamento y razón, es arbitraria y basada en argumentos racistas, impropios de nuestros tiempos. Mal puede invocarse, que por razones de "discriminación positiva" un delincuente pueda verse beneficiado o perjudicado por razones de su origen racial

Estamos en presencia de una discriminación arbitraria cuando la desigualdad no obedece a la razón ni a la justicia” ${ }^{37}$.

\section{Reconocimiento cultural como manifestación del derecho a la igualdad.}

De acuerdo a las bases constitucionales de nuestro ordenamiento jurídico, todos los habitantes de Chile nacen libres e iguales en derechos. Sin embargo, la realidad da cuenta de que sólo algunos grupos tienen la capacidad de ejercer la totalidad de sus derechos y ser agentes de ellos, siendo Chile uno de los países más desiguales del mundo en términos de distribución de ingresos.

En el caso de los pueblos indígenas, la desigualdad social se profundiza a causa del empobrecimiento y del histórico despojo territorial. La Araucanía es la región con las mayores tasas de pobreza e indigencia del país, y al interior de ésta, los indígenas se ubican en la línea de pobreza e indigencia superior al resto de los habitantes de la región, posicionándose como los más pobres entre los pobres. ${ }^{38}$

Esta situación fáctica de desigualdad social se refuerza con la inexistencia de una normativa que apunte a disminuir la situación de exclusión material y cultural en que se encuentran los pueblos originarios. En términos de Garzón López:

“[...] ¿por qué algunas sociedades, culturas o grupos tienen más privilegios, poder o competencia que otros, siendo teóricamente iguales? ¿Cuáles son los fundamentos y justificaciones que sostienen la dominación de unos grupos sobre otros? ¿Por qué culturas asentadas en un mismo territorio desde tiempo inmemorial, como el caso de los pueblos indígenas, siguen, subordinadas a la cultura central? Estas son algunas interrogantes que subyacen en el contexto del multiculturalismo, siendo el reconocimiento público, el respeto a la diferencia y la no discriminación las medidas más socorridas para gestionar la diversidad cultural" ${ }^{\prime 3}$.

Desde la perspectiva aquí defendida, el reconocimiento de la existencia de los derechos de los pueblos indígenas, y de su cultura propia es precisamente una manifestación del reconocimiento del su derecho a la igualdad, en lo que podríamos llamar "el derecho a la igualdad en la diferencia", de quienes son agentes todas aquellos personas que pertenecen a estos pueblos.

\footnotetext{
${ }^{37}$ Oficio de Tribunal Constitucional. Admite a tramitación requerimiento. Fecha 19 de julio, 2000. Cuenta en Sesión 19, Legislatura 342, Senado, en: http://www.leychile.cl/Navegar?idNorma=279441 [visitado el 01.12.2014].

38 Ver Encuesta CASEN 2013 en: http://observatorio.ministeriodesarrollosocial.gob.cl/documentos/Casen2013_Pueblos_Indigenas_13mar15_pu blicacion.pdf

${ }^{39}$ GARZÓN LÓPEZ, Pedro, Multiculturalismo, ciudadanía y derechos indígenas: hacia una concepción decolonial de la ciudadanía indígena, tesis doctoral, Getafe: Universidad Carlos III de Madrid, 2012, p. 39.
} 
Polít. crim. Vol. 10, № 19 (Julio 2015), Art. 12, pp. 362-389.

[http://www.politicacriminal.cl/Vol_10/n_19/Vol10N19A12.pdf]

Esta idea se opone a la versión conservadora que entiende que comprende la igualdad como una garantía de la evitación de cualquier forma de distinción en la aplicación de la ley, sin importar el contenido de esta misma. Esta concepción, presupone que esta garantía de igualdad consiste en el derecho subjetivo que tiene un sujeto de ser tratado jurídicamente de la misma manera que el resto, de estar sometido de una forma idéntica a los otros ante la ley, derecho que les otorga además la facultad de defenderse ante cualquier forma arbitraria distinción. El problema de esta postura es que partiendo de la máxima de que todas las personas son iguales y por lo tanto la ley es igual para todos, confunde la igualdad en derechos, con una situación fáctica de igualdad. Quiero decir con esto que, no por el hecho de que todas las personas tienen los mismos derechos, significa que en la realidad sí somos iguales.

En la realidad, las personas somos distintas social y económicamente, tenemos diferencias de género, de edad y también en nuestras culturas. Es más, una ley que se funda en el principio de la igualdad debería tratar de equiparar estas diferencias.

No es correcto entonces, sostener que cualquier norma que reconozca estas diferencias y les dé un trato diferenciado es una vulneración al derecho a la igualdad ${ }^{40}$. En síntesis, es correcto comprender el principio de igualdad como un mecanismo de interpretación de las normas jurídicas que apunta hacia la justicia, y por lo tanto debe hacer distinciones cuando las circunstancias así lo ameriten.

Por ello, el derecho a la igualdad debe ser comprendido en todas sus manifestaciones, tanto es su versión negativa como la garantía de no ser víctima de diferenciaciones arbitrarias en la aplicación de la ley -en los términos del art. 19 n ${ }^{\circ} 2$ de la Constitución Política-, y también tiene una cara positiva, en cuanto las personas que se encuentran en una situación de desventaja y de diferencia tienen derecho a que la ley las reconozca y les dé un trato acorde a su realidad.

Como lo señalamos anteriormente, pese a los avances en materia de derechos fundamentales en temas de igualdad y reconocimiento cultural, el sistema jurídico nacional tanto a nivel legislativo como judicial no ha desarrollado avances en estos términos, transformándose en un correlato más de una realidad de desigualdad sociocultural.

En particular, la jurisprudencia penal no ha desarrollado en los términos de los artículos 9 y 10 del Convenio 169 una línea argumentativa que tienda a reconocer la cultura indígena en sus decisiones, y en muchas ocasiones, se ha utilizado la incorporación del componente étnico elaborar un discurso jurídico discriminador y basado en prejuicios, como lo expondré en los párrafos siguientes.

\footnotetext{
${ }^{40}$ Esta postura ha sido criticada también por la doctrina constitucionalista nacional: , y por lo tanto se aleja del sentido que tiene la búsqueda de la igualdad, que no es más que la justicia: "Esta perspectiva fue insuficiente e ineficaz ya que omitía toda consideración sociológica como son las circunstancias económicas, sociales, culturales y educativas que condicionaban la vida real de las personas, excluyendo elementos básicos para la comprensión y tratamiento de la realidad social, reproduciendo o acentuando las graves disparidades en el ámbito socio económico." En NOGUEIRA, Humberto, Derechos Fundamentales y Garantías Constitucionales, Tomo II, Santiago: Librotencia, 2008 p. 225.
} 
ROYO, Manuela. "Derecho Penal e interculturalidad como manifestación del principio de igualdad".

\title{
5. Jurisprudencia penal y diferencia cultural.
}

A continuación analizaré algunas sentencias penales, utilizando la nomenclatura creada por Luigi Ferrajoli en su trabajo "Igualdad y Diferencia" ". Este artículo distingue entre distintos paradigmas desde los cuales el Derecho ha abordado el problema jurídico de las situaciones de desigualdad, ya sea de género, religiosas o culturales, frente a las cuales ha respondido con diversas fórmulas o "modelos de configuración jurídica de las diferencias", las cuales podemos también encontrar insertas en sentencias chilenas aplicadas a indígenas.

El primero de ellos corresponde a un modelo de "indiferencia jurídica de las diferencias",42, el cual niega la existencia de diferencias de identidad o culturales dentro de un Estado de Derecho, partiendo de la premisa de que todas las personas ya son iguales. Las diferencias de identidad solo se ignoran, y por lo tanto no se hace mención a esta realidad. Esta es la idea subyacente en la falta de reconocimiento constitucional de los pueblos originarios, y se encuentra en las discusiones parlamentarias ya citadas que niegan todo reconocimiento en materia penal de la diversidad cultural:

\begin{abstract}
“¿Es acaso importante para la víctima y la sociedad, que un determinado delito sea cometido por un individuo de una etnia u otra? Es claro, vuestra Excelencia, que los artículos 9 y 10 del Convenio atentan contra el principio de igualdad ante la ley consagrado en el artículo $19, \mathrm{~N}^{\circ} 2^{\circ}$ de la Constitución, pues constituye en sí una discriminación que carece de fundamento y razón, es arbitraria y basada en argumentos racistas, impropios de nuestros tiempos" $\$$.
\end{abstract}

En nuestra jurisprudencia es posible encontrar un caso paradigmático de negación de las diferencias culturales y la indiferencia ante la realidad indígena de una interviniente. Este fue el de la pastora indígena aymara Gabriela Blas, quien extravió a su hijo en las alturas del altiplano andino en el contexto de sus labores de pastoreo. Producto del extravío el menor murió en las alturas del altiplano y se responsabilizó a su madre por este hecho, siendo condenada por el Tribunal Oral en lo Penal de Arica, como autora de parricidio consumado.

En su teoría del caso la defensa de la pastora aymara argumentó que es costumbre las mujeres indígena el acompañarse de sus hijos en sus labores de pastoreo y dejarlos en un lugar determinado. Sin embargo, el Tribunal desestimó la argumentación de la adecuación social de la conducta realizada por la madre y su pertenencia costumbre indígena, negándose a reconocer el carácter indígena de la imputada y el contexto cultural en que se produjeron los hechos:

(...) el Comisario Juan Carrasco dio cuenta que pidió cooperación a un sicólogo institucional para entender lo que Gabriela percibía y se analizó su estado de sociabilización, por su parte, Ángel Parraguez dio cuenta que estuvo en el interior de la vivienda que ocupaba Gabriela Blas, observando prendas femeninas y documentación en el lugar, tales como toallas higiénicas y su carnet de Fonasa, especie y documentos

\footnotetext{
${ }^{41}$ FERRAJOLI, Luigi, Derechos y garantías, Madrid: Editorial Trotta, 1999, pp. 73-93.

${ }^{42}$ FERRAJOLI, Derechos, cit. nota ${ }^{\circ} 41$, p. 74.

${ }^{43}$ Oficio del Tribunal Constitucional, cit. nota $\mathrm{n}^{\circ} 37$.
} 
Polít. crim. Vol. 10, № 19 (Julio 2015), Art. 12, pp. 362-389.

[http://www.politicacriminal.cl/Vol_10/n_19/Vol10N19A12.pdf]

no propios para quien se dice sufrir de deprivación cultural, de tal entidad que no pudo representarse que el hecho de dejar solo a un niño en un lugar solitario, que ella bien conocía podría acarrearle la muerte, la misma que efectúa la denuncia 28 horas después de la desaparición del niño y no lo hizo en la localidad policial más próxima"44.

La pastora aymara pasó tres años en prisión preventiva, fue condenada a 10 años en un juicio que luego fue anulado, pero en el segundo proceso penal la pena se elevó a 12 años. Tras 6 años de cumplimiento efectivo, Gabriela Blas recibió el indulto presidencial.

Bajo el supuesto de que una mujer indígena no es distinta de una mujer chilena por tener carnet de salud o por usar toallas higiénicas, el tribunal desestimó valorar la lo relevante que era que la condenada estaba actuando conforme a su costumbre, siendo abiertamente indiferente a las diferencias culturales, y por lo tanto omitiendo señalar una circunstancia relevante al momento de decidir sobre la libertad de una persona. Esta negación de la existencia de diferencias culturales finalmente profundiza la realidad ya desigual de la sociedad.

Una forma distinta de ignorar las diferencias culturales es también la "homologación jurídica de las diferencias", en la cual, bajo una intenta asimilar la cultura o identidad diversa a la dominante y de esta forma se neutraliza, en palabras de Ferrajoli "[es] el modelo de la asimilación propio de los ordenamientos liberales, que sin poner en cuestión la parcialidad del sujeto del modelo precedente, lo asumieron como un término "normal" y "normativo" de la igualdad, idóneo para incluir a los demás, sólo en cuanto homologados con él" "45.

Esta perspectiva fue dominante en siglo XX, y particularmente en el ámbito de los derechos de los pueblos originarios, se cristalizó en la denominada teoría indigenista, la cual parte de la base de que los indígenas son un grupo de personas primitivas, que transitan por etapas inferiores de la civilización, y que por lo tanto se hace necesario integrarlos dentro de la sociedad occidental fomentar su propio desarrollo hacia etapas más avanzadas de la civilización $^{46}$.

En Chile esta doctrina se manifestó en la utilización de normas jurídicas de protección propias del Convenio 107 de la OIT, que acuñaba la terminología de "minoría étnica" para referirse a los pueblos indígenas y que abordaban la cuestión indígena desde una perspectiva paternalista.

En materia penal, un caso paradigmático corresponde a una causa por homicidio de un menor ocurrido en el contexto de un maremoto en la localidad de Puerto Saavedra en el año 1960, donde varios imputados mapuches fueron absueltos luego de sacrificar a un niño de la comunidad, en base a la eximente de responsabilidad del artículo $10 \mathrm{~N}^{\circ} 9$ del Código Penal. El Tribunal consideró que al estar en una "etapa de desarrollo inferior" los

\footnotetext{
${ }^{44}$ Sentencia Tribunal Oral en lo Penal de Arica, Rit 221-2009, 11 de octubre del 2010.

${ }^{45}$ FERRAJOLI, Derechos, cit. nota n ${ }^{\circ} 41$, p. 74.

${ }^{46}$ LILLO, Rodrigo, "El Convenio 169 de la OIT y defensa penal de indígenas", Minuta Regional de la Defensoría Penal Pública, n, abril del 2010, p. 7.
} 


\section{ROYO, Manuela. "Derecho Penal e interculturalidad como manifestación del principio de igualdad".}

imputados estaban exentos de culpabilidad, considerando que si bien los imputados indígenas eran imputables y conscientes del carácter de injusto de su conducta, por las circunstancias anormales que se presentaron en esta situación concreta, no se le puede exigir otra conducta debido a su nivel inferior de desarrollo:

"Que la defensa de los mencionados reos alegó en su contestación a la acusación la concurrencia de la eximente de responsabilidad criminal contemplada en el $\mathrm{N}^{\circ} 9$ del artículo 10 del Código Penal, esto es, haber actuado los reos violentados por una fuerza irresistible o impulsados por un miedo insuperable, alegación que debe ser oída por cuanto aparece en las distintas piezas del proceso que el sacrificio del menor LQ fue consumado como medio de "calmar la furia del mar", según términos textuales de los reos y testigos de la causa, mientras se sucedían los acontecimientos del día 22 de mayo y siguientes, que, naturalmente, produjeron en todos los habitantes de la zona afectada una alteración nerviosa que, en el caso de autos, debió tener, necesariamente, mayor gravedad y proporciones, pues se trata de un sector de la población indígena que dio claras demostraciones de estar aún en una etapa de civilización que hace imposible responsabilizarlos por la acción cometida ${ }^{47}$ ".

Otro ejemplo más reciente corresponde a la esgrimida por el Tribunal de Juicio Oral en lo Penal de Santiago en el caso de dos imputadas por el delito de tráfico de drogas -ambas de origen aymara- para calificar ${ }^{48}$ la irreprochable conducta anterior de ellas, considerando que por ser indígenas, tenían un grado inferior de reproche debido a su condición de precariedad y vulnerabilidad, que les hacía menos exigible mantener un comportamiento acorde a la norma penal:

"En efecto, del conjunto de antecedentes aportados ya reseñados y habida consideración de que se trata de personas que pertenecen a la etnia aymara, como se acreditó con la deposición de PJZA, y, teniendo presente además lo dispuesto en el artículo 54 de la denominada "Ley Indígena", es posible atribuir a dicha minorante el carácter que exige el artículo 68 bis del Código Penal para este caso en concreto. Para así decidirlo, se ha considerado que las irreprochables conductas anteriores de los acusados $\mathrm{ChG}$ y $\mathrm{ChC}$, constituyen una conducta excepcional, pues atendidas las particularidades que presentan la vida de estos enjuiciados - probado mediante el testimonio de Zaval Astaburuaga- ha llevado al tribunal al convencimiento de asignarle dicha ponderación especial (....) además, se ha tomado en cuenta el contexto cultural y social en que se desenvuelven las personas de esta etnia, quienes, atendida la precariedad en la que viven por la lejanía con la metrópolis, el aislamiento en el que desarrollan su quehacer, se hacen sujetos más vulnerables para ser utiliza dos por los proveedores y comercializadores de droga, pues es un hecho público y notorio que al estar cercano a las grandes áreas productoras de cocaína, son utilizados como "burreros", todo lo cual hace meritoria una calificación de la conducta irreprochable" ${ }^{\text {, }}$.

\footnotetext{
${ }^{47}$ Considerando $5^{\circ}$, sentencia de 02 de octubre de 1962, causa Rol $\mathrm{N}^{\circ} 24.228$, dictada por doña Ester Valencia Durán, citado por LILLO, "El Convenio", cit. nota n 46.

${ }^{48}$ Calificar una atenuante significa darle un valor excepcional y rebajar la pena asignada a un delito en un grado en los términos del Art. 68 bis del Código Penal.

${ }_{49}$ Causa RIT 24-2006 de 12 de junio de 2006, dictada por la Sala del Cuarto Tribunal de Juicio Oral en lo Penal de Santiago.
} 
Polít. crim. Vol. 10, № 19 (Julio 2015), Art. 12, pp. 362-389.

[http://www.politicacriminal.cl/Vol_10/n_19/Vol10N19A12.pdf]

En ambos casos, si bien se busca llegar a una solución jurídica que sea favorable para los indígenas sometidos al proceso penal, hacen una valoración jurídica que da cuenta de que por su cultura son distintos, pero son menos reprochables por estado de atraso y de menor desarrollo, en comparación con la "normalidad" de quienes no son indígenas.

Un tercer modelo de acuerdo al cual se ha abordado la diferencia cultural, corresponde a la llamada "diferenciación jurídica de las diferencias" reconoce la existencia de diversidad de identidades, pero les asigna un valor distinto y las sitúa de forma asimétrica, situando a unos por sobre otros. Este modelo tiene su origen en los ordenamientos jurídicos propios del siglo XIX, que bajo la perspectiva paternalista del sistema colonial consideraba a los indígenas como incapaces relativos ${ }^{51}$ y por lo tanto les daba un tratamiento diferenciado en relación a los occidentales, diferencias que también se hacían entre hombres y mujeres, entre blancos y negros, y en nuestro caso entre chilenos e indígenas.

Si bien este paradigma de "desigualdad legal", tiene un discurso arcaico, hoy sus resabios se proyectan en el ordenamiento jurídico contemporáneo, de la forma que se describe a continuación:

"Este es el paradigma discriminatorio de los ordenamientos jerarquizados de casta o clases propios de las fases más arcaicas de las experiencias jurídicas y todavía dominante en el mundo jurídico premoderno. Pero también el paradigma que persiste en los orígenes de la modernidad, cuando la igualdad y los consecuentes derechos "universales" aparecen pensados y proclamados, en las primeras constituciones liberales, únicamente al sujeto blanco, macho y propietario",52.

La utilización de este tipo de razonamiento en la jurisprudencia actual da cuenta de la subsistencia de una mirada colonial hacia la cultura indígena, situación que hoy se profundiza cuando existe un conflicto social de reivindicación de derechos como es el caso del pueblo mapuche en la Araucanía chilena.

Ahora, si bien la legislación actual no declara la superioridad racial ni étnica en los términos en que se hacía en siglo XIX o en épocas anteriores, sí es posible encontrar argumentaciones que denotan un sesgo racista que le otorga un valor inferior a la cultura indígena, y lo que es peor, también es pesquisable la utilización de la herramienta penal como mecanismo de diferenciación, lo que ha ocurrido en contextos de conflicto social conflicto mapuche. Tal como lo grafica Myrna Villegas en su artículo "El Mapuche como enemigo en el Derecho (Penal). Consideraciones desde la biopolítica y el derecho penal del

\footnotetext{
${ }^{50}$ FERRAJOLI, Derechos, cit. nota ${ }^{\circ} 41$, p. 74.

51 "Las "Leyes de Indias" están llenas de referencias a la necesidad del buen trato y a la conversión pacífica de los indios, hechas siempre desde la convicción más firme de la superioridad de la propia cultura. Los indios debían ser civilizados, o sea, debían incorporarse a la cultura española. En la Constitución chilena de 1822 se establecen entre las competencias del Congreso la de "cuidar de la civilización de los indios del territorio" en: CASTILLO, Jesús, "El estatuto jurídico de los indígenas en las constituciones hispanoamericanas del período de la emancipación", Revista de Estudios Histórico Jurídicos $\mathrm{N}^{\circ} 35$ (2013), p.436, disponible en: http://www.scielo.cl/scielo.php?pid=S0716-54552013000100013\&script=sci_arttext [visitado el 01.12.2014].

${ }^{52}$ FERRAJOLI, Derechos, cit. nota ${ }^{\circ} 41$, p. 74.
} 


\section{ROYO, Manuela. "Derecho Penal e interculturalidad como manifestación} del principio de igualdad".

enemigo" el Estado chileno en respuesta a la emergencia indígena y a sus reivindicaciones propias, se han seguido procesos criminales de excepción, que dan cuenta de una utilización selectiva de los mecanismos más fuertes del derecho penal, para el control social del movimiento indígena:

"La represión que ejerce el Estado en el conflicto mapuche es selectiva. Se dirige solo a las resistencias que se han organizado al margen de las vías institucionales, tendiendo a neutralizarlas o suprimirlas, no a todo el pueblo mapuche, por lo que en mi opinión es incorrecto -desde la objetividad- hablar de criminalización de las demandas mapuche y es más correcto hablar de "criminalización de las resistencias" al biopoder. Y esta criminalización se ejerce usando y abusando de las prerrogativas que entrega la legislación, tanto común, como especial. Concretamente el control penal que se ha ejercido sobre el conflicto, particularmente desde la transición democrática, ha ido paulatinamente deslizándose por la pendiente del autoritarismo., 53

Ejemplo de ello ha sido la aplicación de la Ley de Seguridad del Estado y posteriormente con la aplicación de la Ley Antiterrorista en contra de integrantes del pueblo mapuche, en causas donde se han ventilado causas penales en conflictos de connotación indígena. Así lo determinó la Corte Interamericana de Derecho Humanos, que sancionó al Estado Chileno el 29 de mayo del 2014 por el caso "Norin Catriman y otros", en el cual 8 dirigentes de comunidades mapuche fueron condenados a penas de entre 5 y 10 años por los delitos de incendio y tentativa de incendio, calificados de terroristas, en hechos ocurridos en los años 2001 y 2002 en las regiones chilenas de Bío Bío y La Araucanía.

El origen de la condena al Estado chileno se inicia justamente por una sentencia penal del Tribunal Oral en lo Penal de Angol, que llegó a una convicción condenatoria en los siguientes términos:

"[...] las acciones que causaron estos delitos demuestran que la forma, métodos y estrategias empleadas, tenían una finalidad dolosa de causar un estado de temor generalizado en la zona.

Los ilícitos antes referidos están insertos en un proceso de recuperación de tierras del pueblo mapuche, el que se ha llevado a efecto por vías de hecho, sin observar la institucionalidad y legalidad vigente, recurriendo a acciones de fuerza previamente planificadas, concertadas y preparadas por grupos exacerbados que buscan crear un clima de inseguridad, inestabilidad y temor en diversos sectores de la octava y novena regiones. Estas acciones se pueden sintetizar en la formulación de exigencias desproporcionadas, hechas bajo presión por grupos beligerantes a los dueños y propietarios, a quienes se les advierte que sufrirán diversos tipos de atentados en caso de no acceder a sus requerimientos, muchas de estas amenazas se han materializado mediante ataques a la integridad física, en acciones de robo, hurto, incendio, daños y ocupaciones de tierras, que han afectado tanto a los individuos y bienes de diversas personas dedicadas a las actividades agrícolas y forestales de esta zona del país.

\footnotetext{
53 VILLEGAS, Myrna, "El Mapuche como enemigo en el Derecho (Penal). Consideraciones desde la biopolítica y el derecho penal del enemigo" en: Portal Iberoamericano de Ciencias Penales, disponible en: http://www.cienciaspenales.net/descargas/idp_docs/doctrinas/mapuche\%20actor\%20social\%20enemigo.pdf [visitado el 18. 02.2015], p. 13.
} 
Polít. crim. Vol. 10, № 19 (Julio 2015), Art. 12, pp. 362-389.

[http://www.politicacriminal.cl/Vol_10/n_19/Vol10N19A12.pdf]

Luego prosigue este fallo:

[...] Respecto a la participación de ambos enjuiciados es preciso considerar lo siguiente:

1.- Como antecedentes generales y de acuerdo a la prueba aportada durante el juicio por el Ministerio Público y los querellantes particulares, es un hecho público y notorio que en la zona, desde hace un tiempo a la fecha, están actuando organizaciones de hecho que usando como argumento reivindicaciones territoriales, realizan actos de violencia o incitan a ellos. Entre sus métodos de acción se emplea la realización de diversos actos de fuerza que se dirigen contra empresas forestales, pequeños y medianos agricultores, todos los cuales tienen en común ser propietarios de terrenos contiguos, aledaños o cercanos a comunidades indígenas que pretenden derechos históricos sobre las mismas. Tales acciones apuntan a la reivindicación de tierras estimadas como ancestrales, siendo la ocupación ilegal un medio para alcanzar el fin más ambicioso, a través de ellas se irán recuperando parte de los espacios territoriales ancestrales y se fortalecerá la identidad territorial del Pueblo Mapuche. Así se desprende del testimonio conteste de los ofendidos Juan y Julio Sagredo Marin, Juan Agustín Figueroa Elgueta y Juan Agustín Figueroa Yávar, sustentados por el atestado de Armin Stappung Schwarzlose, Gerardo Jequier Salí, Jorge Pablo Luchsinger Villiger, Antonio Arnaldo Boisier cruces y Osvaldo Moisés Carvajal Rondanelli, analizadas.

Analizando estos considerandos la Corte Interamericana de Derechos Humanos condenó al Estado chileno al considerar que se utilizaron razonamientos discriminatorios para condenar a los comuneros mapuche, basados en prejuicios de connotación racista que vulneraban el derecho a la igualdad, además de las afectaciones de otras garantías fundamentales:

"Adicionalmente, la Corte encontró que en la fundamentación de las sentencias condenatorias se utilizaron razonamientos que denotan estereotipos y prejuicios, lo cual configuró una violación del principio de igualdad y no discriminación y el derecho a la igual protección de la ley (supra párrs. 223 a 228 y 230). (...) Todo ello hace que sean condenas arbitrarias e incompatibles con la Convención Americana. ${ }^{54}$

Por último, podemos encontrar otra fórmula con la cual el derecho puede abordar el conflicto jurídico que representa la existencia de diferencias, este corresponde a la "valoración jurídica de las diferencias". De acuerdo a Ferrajoli este modelo se fundamenta en el principio normativo de igualdad en derechos fundamentales y consiste en el reconocimiento y valoración de las características propias de cada individuo como una manifestación correcta del principio de igualdad:

“La igualdad en derechos fundamentales resulta así configurada como el igual derecho de todos a la afirmación y a la tutela de la propia identidad, en virtud del igual valor asociado a todas las diferencias que hacen de cada persona un individuo diverso de todos los otros y de cada individuo una persona como todas las demás. Pero este igual derecho es, precisamente, una norma destinada como todas las normas a ser violada en

\footnotetext{
${ }^{54}$ CORTE INTERAMERICANA DE DERECHOS HUMANOS, Caso Norín Catriman y otros, cit. nota ${ }^{\circ} 8$, p.137.
} 
ROYO, Manuela. "Derecho Penal e interculturalidad como manifestación del principio de igualdad".

algún grado y medida. De ello se sigue que las diferentes identidades pueden ser reconocidas y valorizadas en la misma medida que, partiendo no de la proclamación de su abstracta igualdad, sino del hecho de que pesan en las relaciones sociales como factores de desigualdad en violación de la norma sobre la igualdad, se piensen y se elaboren no sólo las formulaciones normativas de los derechos sino también sus garantías de efectividad"55.

Por ello, la igualdad debe ser un principio jurídico bajo el cual se deben interpretar las normas penales, donde se reconozcan las diferencias en los hechos, pero la igualdad en derechos.

En el caso de los pueblos indígenas, y en particular de la cultura mapuche se debe reconocer que previo al proceso de colonización y de despojo cultural, estos contaba con un marco institucional, un sistema normativo y unos mecanismos procedimentales de regulación propia $^{56}$ que hoy -bajo la lógica de la resistencia simbólica cultural-persiste desde la memoria colectiva. Existe en las culturas indígenas un sustrato de conocimientos ancestrales propios y por lo tanto corresponde reconocerlo en materia de derechos como manifestación del derecho a la igualdad.

Esta propuesta ha sido criticada por la doctrina nacional en consideración a que el reconocimiento de una normatividad cultural distinta a la occidental atenta contra el principio de unidad jurídica, cuya consecuencia sería la fragmentación del derecho penal y la pérdida de eficacia de este como herramienta de conminación social hacia la adscripción hacia determinadas normas de conducta:

“(...) uno de los mayores problemas que se pueden presentar con la instauración de derechos colectivos, como por ejemplo, el establecimiento de sistemas judiciales atendiendo al grupo cultural es el riesgo a la generación de guetos dentro de una sociedad, que puede derivar en un desmembramiento social. Precisamente en una sociedad en la que existen diversas identidades normativas, difícilmente desde una perspectiva preventivo general puede ser eficaz el Derecho Penal. Es decir, mediante el reconocimiento de la diversidad cultural como un derecho colectivo y la disposición de los pertenecientes a tales grupos a buscar vías propias de solución de conflictos fragmentación del derecho penal por la presencia de derechos penales propios- se terminaría por admitir ciertos comportamientos intolerables para el resto del componente social ${ }^{57}$."

Sin embargo, esta idea de unidad jurídica entendida como homogeneidad pierde sentido en el derecho actual, que reconoce diversas fuentes del derecho (tratados internacionales, reglamentos administrativos, etc.) que en ocasiones incluso entran en conflicto con otras normas y que el mismo derecho intenta resolver:

\footnotetext{
${ }^{55}$ FERRAJOLI, Derechos, cit. nota ${ }^{\circ} 41$, p. 76.

${ }^{56}$ Bajo el modelo del Rakizuam como estilo reflexivo y racionalidad propia, materializado operacionalmente desde el AzMapu, como sistema normativo propio de la cultura mapuche.

${ }^{57}$ CARNEVALI, Raúl, "El multiculturalismo: un desafío para el derecho penal moderno", Política Criminal $n^{\circ} 3$ (2007), p. 22, en: http://www.politicacriminal.cl/n_03/a_6_3.pdf [visitado el 06.12.2014].
} 
Polít. crim. Vol. 10, No 19 (Julio 2015), Art. 12, pp. 362-389.

[http://www.politicacriminal.cl/Vol_10/n_19/Vol10N19A12.pdf]

\begin{abstract}
"Este principio establece que, puesto que el derecho tiene una única fuente, la cual es internamente homogénea, el derecho constituye una totalidad bien definida que puede ser conocida en toda su dimensión en cualquier momento de creación o interpretación del derecho gracias a los métodos que la ciencia jurídica moderna desarrolló y puso al servicio del derecho y los juristas. También este principio es hoy cuestionado por muchos factores. Después de décadas de incesante producción jurídica; de caída en desuso de muchas normas sin que se haya producido su revocación formal; de decisiones superpuestas a lo largo del tiempo, a veces contradictorias, de los tribunales superiores; después de sucesivas sujeciones de los países periféricos a las imposiciones políticas y jurídicas internacionales, a menudo en contradicción con su derecho ordinario, incluyendo su derecho constitucional; por todas estas razones hoy resulta prácticamente imposible determinar con exactitud y exhaustividad todo el derecho efectivamente vigente en un momento dado"58.
\end{abstract}

Es más, bajo el alero del Convenio 169 y de las modificaciones de las Constituciones y leyes, distintos países latinoamericanos reconocen las justicias indígenas sin perder por ello de eficacia normativa, como en el caso de Colombia, Bolivia, Ecuador y otros.

Por otro lado, y en relación al fin de prevención general del derecho penal, no parece que la norma penal pierda eficacia por el hecho de incluir en sus consideraciones variantes culturales, esto implicaría suponer que en las sociedades indígenas no existe una valoración análoga de los mismos bienes jurídicos que en la sociedad occidental, que sus normas no tienen efectos en quienes adscriben a ellas, y por lo tanto carecerían de toda legitimidad. Sin embargo parece más lógico que las normas con pertinencia cultural tienen un mayor efecto comunicacional en el ámbito preventivo general que normas ajenas a la realidad de sus destinatarios. Esto nos lleva a preguntarnos ¿Qué validez tiene una norma basada en la desigualdad? ¿De qué manera podría ser efectiva una norma que no incorpora el sistema valórico propio de una cultura?

\title{
6. Consideraciones finales.
}

La multiculturalidad corresponde a un fenómeno contemporáneo que en nuestro continente tiene sus raíces en una historia reciente de colonización y despojo hacia los pueblos originarios, ya que la construcción del Estado chileno en el territorio mapuche solo se inicia a fines del siglo XIX, en una guerra que no sólo arrebató a los mapuche de sus tierras, sino que también acalló las representaciones colectivas y manifestaciones culturales propias de su subjetividad, imponiendo un sistema normativo ajeno a las costumbres indígenas.

Cuando hablamos de coexistencia cultural, ello no quiere decir que sea una convivencia simétrica o en plena igualdad, sino que es una realidad compleja, donde sigue latente una historia de conflicto, que hoy toma cuerpo en nuevas reivindicaciones y conflictos por la recuperación del territorio mapuche, realidad en la cual el ordenamiento jurídico debe ser un instrumento para el reconocimiento de la dignidad de los pueblos indígenas y de sus derechos.

\footnotetext{
${ }^{58}$ DE SOUSA SANTOS, Justicia indígena, cit. nota ${ }^{\circ} 34$, p. 17.
} 
ROYO, Manuela. "Derecho Penal e interculturalidad como manifestación del principio de igualdad".

En base una idea de igualdad vinculada a la justicia social, y en concordancia con los tratados de derechos humanos ratificados por el Estado chileno y el Convenio 169 de la OIT, se hace necesario reconstruir espacios dentro del sistema normativo que permita incorporar mecanismos de resolución de conflictos donde sea trascendentes elementos de hecho o de derecho propios de las culturas originarias, los cuales pueden ser incorporados por diversas vías en materia penal.

Para ello, es posible asumir una postura intercultural que valore los elementos propios del mundo indígena en concordancia con el sistema normativo occidental, sin caer en esencialismos culturales ni menos en el universalismo liberal, reconociendo que el Estado no es el único ente generador de normas, sino que ellas también pueden surgir de la cultura y de la cosmovisión indígena.

El desafío para el derecho penal es encontrar mecanismos para valorar jurídica de las diferencias, como una forma de generar espacios de reconocimiento de derechos y de construcción de un ordenamiento jurídico que aporte a la igualdad social, siempre teniendo como horizonte el ejercicio del derecho a la autodeterminación de los pueblos, vinculado con un ideal de justicia y equidad social. 
Polít. crim. Vol. 10, № 19 (Julio 2015), Art. 12, pp. 362-389.

[http://www.politicacriminal.cl/Vol_10/n_19/Vol10N19A12.pdf]

\section{BIBLIOGRAFÍA}

BARRIENTOS PARDO, Ignacio, "Licitud del porte y uso de la hoja de coca", Politica Criminal N`5 (2008), pp.1-30, en: http://www.politicacriminal.cl/n_05/a_4_5.pdf

BENGOA, José, La emergencia indígena en América Latina, Santiago: Fondo de Cultura Económica, 2007.

CARNEVALI, Raúl, "El multiculturalismo: un desafío para el derecho penal moderno", $\begin{array}{lllllll}\text { Politica Criminal } & \mathrm{N}^{\circ} & 3 & \text { (2007), } & \text { p. } & 22, & \text { en: }\end{array}$ http://www.politicacriminal.cl/n_03/a_6_3.pdf

CASTILLO, Jesús, "El estatuto jurídico de los indígenas en las constituciones hispanoamericanas del período de la emancipación", Revista de Estudios Histórico Jurídicos $\quad \mathrm{N}^{\circ} \quad 35 \quad$ (2013), p. 436, disponible en: http://www.scielo.cl/scielo.php?pid=S0716-54552013000100013\&script=sci_arttext [visitado el 01.12.2014]

CEPAL, "Desigualdades territoriales y exclusión social del pueblo mapuche en Chile", (2012), p. 28, en: http://www.cepal.org/publicaciones/xml/3/46283/2012-79DesigualdadesterritorialesWEB.pdf

CORTE INTERAMERICANA DE DERECHOS HUMANOS, Caso Norín Catriman y otros (dirigente, miembros y activista del pueblo indígena mapuche vs. Chile, en: http://www.corteidh.or.cr/docs/casos/articulos/seriec_279_esp.pdf, p.137.

CURY, Enrique, Derecho Penal. Parte General, Santiago: Ediciones Universidad Católica de Chile, 2001.

DE SOUSA SANTOS, Boaventura, Justicia indígena, Plurinacionalidad e interculturalidad en Bolivia, La Paz: Ediciones Abya-Yala, 2012.

ESTERMANN, Josef, Filosofía Contemporánea, La Paz: Ed. Tika y Teko, 2011.

FERRAJOLI, Luigi, Derechos y garantías, Madrid: Editorial Trotta, 1999.

GARGARELLA, Roberto, "El derecho y el castigo: de la injusticia penal a la justicia social”, en: http://e-archivo.uc3m.es/bitstream/handle/10016/17097/DyL-2011-25gargarella.pdf? sequence $=5$

GARZÓN LÓPEZ, Pedro, Multiculturalismo, ciudadanía y derechos indígenas: hacia una concepción decolonial de la ciudadanía indígena, tesis doctoral, Getafe: Universidad Carlos III de Madrid, 2012.

HURTADO POZO, José, "El indígena ante el derecho penal: el caso peruano", Anuario 2010, en: https://www.unifr.ch/ddp1/derechopenal/articulos/a_20080526_05.pdf [visitado el 12.05.2014], pp. 59 y ss.

JAKOBS, Gunther, Estudios de Derecho Penal, Madrid: Editorial Civitas, 1997.

LILLO, Rodrigo, "El Convenio 169 de la OIT y defensa penal de indígenas", Minuta Regional de la Defensoría Penal Pública, n²1, abril del 2010.

MARIMAN, Pablo, "Elementos de historia mapuche", en: http://www.ihes.com/mar/mp1.htm, p.3, [visitado el 19.01.2014].

MEREMINSKAYA, Elina, "El Convenio 169 de la OIT sobre pueblos indígenas y tribales: Derecho internacional y experiencias comparadas", Estudios Públicos, n 121 (2011).

MEZA-LOPEHANDÍA, Matías, "El Convenio N 169 de la OIT en el sistema normativo chileno", en: VV.AA., Las Implicancias de la Ratificación del Convenio $N^{\circ} 169$ de la OIT en Chile, en: http://www.observatorio.cl/sites/default/files/biblioteca/libro_ley169.pdf 
ROYO, Manuela. "Derecho Penal e interculturalidad como manifestación del principio de igualdad".

NOGUEIRA, Humberto, Derechos Fundamentales y Garantías Constitucionales, Tomo II, Santiago: Librotencia, 2008.

PINTO, Jorge, La formación del Estado y la nación y el pueblo mapuche. De la inclusión a la exclusión, Santiago: DIBAM, 2003.

PEÑA, Silvia, "Las raíces histórico culturales del derecho penal chileno", Revista de Estudios Historico-Juridicos, $\quad \mathrm{N}^{\circ} \quad 7 \quad$ (1982), http://www.restudioshistoricos.equipu.cl/index.php/rehj/article/viewFile/97/95, pp. 312 y ss. [visitado el 28.10.2014].

QUIJANO, Aníbal, "Colonialidad del poder, eurocentrismo y América Latina", en: LANDER, Edgardo (Comp.), La colonialidad del saber: eurocentrismo y ciencias sociales. Perspectivas Latinoamericanas. Buenos Aires: CLACSO, Consejo Latinoamericano de Ciencias Sociales, 2000.

ROXIN, Claus, Derecho Penal, Parte General, España: Editorial Civitas, 1999.

, "El concepto de bien jurídico como instrumento de crítica legislativa sometido a examen”, Revista Electrónica de Ciencia Penal y Criminología, 우 15 (2013), p. 1, disponible: en http://criminet.ugr.es/recpc/15/recpc15-01.pdf

SALGADO, Juan Manuel, "Cómo la práctica procesal anula los derechos indígenas", en: OLEA, Helena (Ed.), Derecho y Pueblo Mapuche. Aportes para la discusión. Santiago: Centro de Derechos Humanos UDP, 2013.

SEMPER, Frank, "Los derechos de los pueblos indígenas de Colombia en la jurisprudencia de la Corte constitucional" en http://www.juridicas.unam.mx/publica/librev/rev/dconstla/cont/2006.2/pr/pr3.pdf

STAVENHAGEN, Rodolfo, "Los derechos de los indígenas: algunos problemas conceptuales", Nueva Antropología Vol. XIII, N 43 (1992).

VILLEGAS, Myrna, "El Mapuche como enemigo en el Derecho (Penal). Consideraciones desde la biopolítica y el derecho penal del enemigo", en: Portal Iberoamericano de Ciencias

Penales http://www.cienciaspenales.net/descargas/idp_docs/doctrinas/mapuche\%20actor\%20s ocial\%20enemigo.pdf [visitado el 18. 02.2015].

, "Entre la exculpación y la justificación. Apuntes de legislación comparada latinoamericana sobre pluralismo jurídico y derecho penal", Revista de Derecho (Valdivia) Vol. XXV, N² (2012).

WOLKMER, Antonio Carlos, Pluralismo Jurídico. Fundamentos de una nueva cultura del derecho, Madrid: Editorial MAD, 2006. 